\title{
Editorial
}

\section{Consolidating Strengths}

I remember receiving a wonderful message from Cambridge University Press around three years ago - an invitation to take over as Editor of Medical History. I accepted almost instantaneously, but remember being nervous about the task at hand. At least as nervous as I had been whilst walking into a cage containing around fifty teenaged lions and lionesses with a gamekeeper in charge of an animal orphanage on the outskirts of Port Elizabeth in South Africa.

The editorial responsibilities appeared challenging to say the least. Moving the editorial office and publishing base with access to piecemeal paperwork about past activities promised to be a tough assignment. The Press and I shared ambitious plans for internationalisation, which ensured that we would be required to plan and work in new ways. I was tasked with creating an editorial board composed of excellent scholars who were pioneering new approaches to studying the history of medicine and the medical humanities within their institutional and national contexts, whilst also being involved in international collaborations. The Open Access issue needed careful deliberation and negotiation.

I need not have been overly worried. Colleagues at Cambridge University Press and its Syndicate were enormously supportive, and eased the complexities of complex administrative and legal procedures. The Wellcome Trust's support for relocating the journal and making exceptional Open Access facilities was invaluable. The appointment of an excellent Assistant Editor and other editorial colleagues was a tremendous boost, and the help offered by our excellent collective of editorial advisors and reviewers made a world of difference to our activities, as we dealt with a huge amount of inherited and new activity. I remain deeply grateful to each and every one of you for your goodwill and support.

This is also a time to consolidate the gains we have made over the last three years. Just before I took over formally as Editor, the Press and I agreed to reconstitute the editorial advisory board on a regular basis, mainly to ensure that new energies and ideas help the journal forge ahead. While we are sorry to bid goodbye to some of our advisors, we do look forward to working with them again in the future. At the same time, we welcome a new cohort of excellent scholars into the advisory board, in the knowledge that we will gain from their expertise and counsel over the approaching three years.

Medical History remains deeply committed to making its contents openly available, and I welcome the collaborations between the Wellcome Trust and the Press in this regard. Colleagues at PubMed Central have been important allies, and we look forward to working closely with them. All of us are happy with data on readership, download, impact factor and subscriptions, but it would be foolhardy to rest on these successes. Considering the amount of investment that has gone into this academic project we believe in the need to do more. I am delighted to report that the Press supports these plans to expand the scope of our work. It remains committed to further internationalisation and all of us are delighted to welcome Dr Liew Kai Khiun of Nanyang Technological University, Singapore, 
as a new Media Reviews Section co-editor. He will, we are certain, help us broaden the journal's gaze in more ways than one. Medical History has provided a huge volume of material for free use through PMC. In the coming months, we will draw upon this rich archive, which goes back many years, to provide collections of articles on some themes that are currently considered important. To kick these new activities off, we have invited Dr Henrice Altink to put together some landmark articles dealing with the history of TB for release in February 2015; a collection that she writes about in the short piece that follows this editorial. We will consolidate her excellent work by encouraging members of the editorial advisory board, and the journal's supporters all over the world, to present more such collections in the future.

Medical History is in good health; this would not have been possible without the assistance of many people. Scholars who publish with us, academics who assess the quality of submissions for us, and our many readers who also inform their peers about the scholarship showcased by us. The journal's community of editors extends thanks to you all.

\section{SANJOY BHATTACHARYA}

Department of History and the Centre for Global Health Histories, University of York, UK

Email: sanjoy.bhattacharya@york.ac.uk 